\title{
BMJ Open Six-year trajectories of post-traumatic stress and severe psychological distress symptoms and associations with timing of trauma exposure, ongoing adversity and sense of injustice: a latent transition analysis of a community cohort in conflict-affected Timor-Leste
}

\author{
AK Tay,,${ }^{1,2}$ S Rees,,${ }^{1,2}$ Z Steel, ${ }^{3}$ N Tam,,${ }^{1,2}$ Z Soares, ${ }^{4}$ C Soares, ${ }^{4}$ DM Silove ${ }^{1,2}$
}

To cite: Tay AK, Rees S, Steel Z, et al. Six-year trajectories of post-traumatic stress and severe psychological distress symptoms and associations with timing of trauma exposure, ongoing adversity and sense of injustice: a latent transition analysis of a community cohort in conflictaffected Timor-Leste. BMJ Open 2016;6:e10205. doi:10.1136/bmjopen-2015010205

- Prepublication history and additional material is available. To view please visit the journal (http://dx.doi.org/ 10.1136/bmjopen-2015010205).

Received 7 October 2015 Revised 15 December 2015 Accepted 8 January 2016

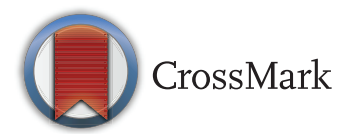

For numbered affiliations see end of article.

Correspondence to Dr AK Tay; alvin.tay@unsw.edu.au

\section{ABSTRACT}

Objectives: To identify the 6-year trajectories of posttraumatic stress symptoms (PTSS) and psychological distress symptoms, and examine for associations with timing of trauma exposure, ongoing adversity and with the sense of injustice in conflict-affected Timor-Leste.

Setting: A whole-of-household survey was conducted in 2004 and 2010 in Dili, the capital of Timor-Leste.

Participants: 1022 adults were followed up over 6 years (retention rate $84.5 \%$ ). Interviews were conducted by field workers applying measures of traumatic events (TEs), ongoing adversity, a sense of injustice, PTS symptoms and psychological distress.

Results: Latent transition analysis supported a 3-class longitudinal model (psychological distress, comorbid symptoms and low symptoms). We derived 4 composite trajectories comprising recovery (20.8\%), a persisting morbidity trajectory $(7.2 \%)$, an incident trajectory $(37.2 \%)$ and a low-symptom trajectory $(34.7 \%)$. Compared with the low-symptom trajectory, the persistent and incident trajectories reported greater stress arising from poverty and family conflict, higher TE exposure for 2 historical periods, and a sense of injustice for 2 historical periods. The persistent trajectory was unique in reporting greater TE exposure in the Indonesian occupation, whereas the incident trajectory reported greater TE exposure during the later internal conflict that occurred between baseline and follow-up. Compared with the low-symptom trajectory, the incident trajectory reported a greater sense of injustice relating to the periods of the Indonesian occupation and independence. The persistent trajectory was characterised by a sense of injustice relating to the internal conflict and contemporary times. The recovery trajectory was characterised by the absence of these risk factors, the only difference from the low-symptom trajectory being that the former reported a sense of injustice for the period surrounding independence.

Conclusions: Our findings suggest that the timing of both TE exposure and the focus of a sense of injustice

\section{Strengths and limitations of this study}

- The study is novel in following up a large community cohort over 6 years, with a high response and retention rate.

- The application of latent transition analysis is novel in the postconflict field, allowing examination of trajectories of symptoms that define groups that may have differential needs.

- Mental health measures were systematically adapted to the culture and language and validated against a structured clinical interview.

- We were not able to determine fully whether the persisting group experienced chronic, fluctuating or the recurrence of symptoms from baseline to follow-up.

- Anamnestic bias and fear of the traumatising effects of recall may distort reporting of traumatic events, although the pattern of exposure documented is consistent with the known history of Timor-Leste.

may differentiate those with persisting and new-onset mental health morbidity in settings of recurrent conflict.

\section{INTRODUCTION}

Relatively few longitudinal studies have traced the course of traumatic stress symptoms over extended periods of time in lowincome and middle-income countries exposed to mass conflict. With one exception, ${ }^{1}$ the study follow-up periods have been restricted to 3 years or less, ${ }^{2-4}$ and the focus has been on broad symptom outcomes 
examined across the sample as a whole. The present study in Timor-Leste is novel in following up a large sample over 6 years (2004-2010), a timeframe that included a period of recurrent internal conflict. We applied latent transition analysis (LTA) to define subpopulations with distinctive symptom trajectories, the aim being to characterise these groups by the extent and timing of trauma exposure, the sense of injustice related to distinct historical periods and the extent of adversity in their ongoing lives.

Research in high-income countries has identified a core set of post-traumatic stress symptom (PTSS) trajectories follow trauma, including subpopulations showing patterns of persisting symptoms, recovery, delayed or late-onset symptoms, and consistently low symptoms over time. $^{5-7}$ Whether these trajectories reflect a universal pattern of responsiveness to trauma that is general to human populations in all settings or are context-specific remains to be determined. Longitudinal studies of populations at high risk of recurrent trauma and ongoing adversity, such as those residing in low-income and middle-income, postconflict countries, may throw new light on the extent to which contextual factors influence PTS trajectories over time.

Timor-Leste exemplifies a country exposed to recurrent conflict and adversity. Indonesia invaded TimorLeste in 1975, occupying the territory until 1999, a period marked by widespread violence, torture, rape, extrajudicial killings, famine, atrocities and mass displacements. ${ }^{8}$ A humanitarian emergency in 1999 following a vote on independence resulted in the destruction of much of the infrastructure of the country by Indonesian supported militia. ${ }^{9}$ Following the restoration of peace by the United Nations, Timor-Leste achieved national independence in 2002. In 2006-2007, the midpoint of our follow-up study, a further outbreak of conflict occurred, involving opposing factions within the country, leading to destruction of property, injuries, deaths and mass internal displacement.

Our 6-year longitudinal study of two communities in Timor-Leste ${ }^{10}$ found a sevenfold increase in PTSS and a threefold increase in severe psychological distress. Further clarification is needed, however, about the distinctive symptom trajectories shown by different subpopulations and, in particular, the contextual factors that accounted for the dramatic increase in the prevalence of key mental health indices over time. Past studies in the field, including in Timor-Leste, have suggested that cumulative trauma ${ }^{11}$ and ongoing adversity (poverty and family/community conflict) are important factors in exacerbating symptoms of PTS and psychological distress, ${ }^{10}$ but most past inquiries have been limited by their cross-sectional designs. ${ }^{12-14}$ The unique aspect of our inquiry is its longitudinal design and the intercession of a recurrent period of conflict (2006-2007) at the midpoint of follow-up, exposing our study population to further trauma. An additional factor which we explore is the influence of the sense of injustice on symptom trajectories, focusing on relevant historical periods in which the population was exposed to human rights abuses and severe deprivations. ${ }^{14}$

The broad aim of this further analysis of our longitudinal study in Timor-Leste was to identify trajectories of PTSS and severe psychological distress over the 6-year follow-up period. We anticipated identifying the polar extremes reported in other studies in high-income countries, that is, a persisting high-symptom and low-symptom class, respectively. In addition, we hypothesised that a substantial subpopulation would exhibit first-onset symptoms in response to exposure to trauma during the internal conflict that occurred between baseline and follow-up. Overall, we anticipated that the subpopulations with adverse symptom trajectories (persisting or new-onset symptoms) would be characterised by more severe and time extensive exposure to trauma, a sense of injustice spanning more than one historical period, and more extreme experiences of ongoing adversity.

\section{METHODS}

\section{Sample and procedures}

Our 2004 whole-of-household survey involved all men and women (18 years and older) residing in two administrative units (sucos) in Dili, the capital of Timor-Leste, and a rural setting 1 hour away. Both locations were directly affected by mass conflict during the Indonesian occupation and subsequently, by the internal conflict of 2006-2007. Our analytic sample includes the cohort completing the baseline (2004) and follow-up (20102011) surveys. In both surveys, we visited households up to five times to maximise participation. At follow-up, we traced those who had relocated within the country based on information provided by families, village chiefs and other informants.

\section{Measures}

\section{Exposure to conflict-related traumatic events}

We assessed 23 conflict-related traumatic events (TEs), drawn from the Harvard Trauma Questionnaire (HTQ) and modified to the context of Timor-Leste. ${ }^{15}$ We measured two epochs of TEs at baseline (the Indonesian period and humanitarian crisis; the period surrounding independence in 2002); and at follow-up, the period of internal conflict (2006-2007). Items included political imprisonment, assault, torture, witnessing murder, exposure to atrocities, losses of family or close others, and severe deprivation of medical care for self or others. A trauma count was generated for each of the three historical periods by assigning a score of 1 for each endorsed TE type.

\section{Sense of injustice}

Respondents identified the worst act/condition of injustice they experienced for each of the Indonesian occupation (1975-1999), the period of independence and for contemporary times (which included the most recent 
period of internal conflict). The events were ones that directly impacted on the person, involving politically motivated murder, assault and human rights violations experienced by themselves or close others during the earlier epochs of conflict, and conditions of extreme deprivation for the contemporary period. Once an event was nominated, participants indicated whether the experience led to a persisting sense of injustice, and if so, whether these experiences caused them ongoing distress. Responses were scored for each period as 0: no event nominated; 1: experienced an unjust event; 2: experienced an event and persisting sense of injustice; and 3: experienced an event, persisting sense of injustice and associated distress.

\section{PTSS and psychological distress}

PTSS were assessed at baseline and follow-up using the $\mathrm{HTQ}^{15}$ comprising 16 items scored on a four-point scale $(0=$ none, $1=$ some of the time, $2=\mathrm{a}$ lot of the time, $3=$ most of the time). We calibrated the HTQ against a gold standard structured clinical interview, ${ }^{16}$ generating a cut-off score of 2.2 as indicative of a possible diagnosis of post-traumatic stress disorder (PTSD). In the present study, the internal reliability for PTSS items was 0.95 .

To assess psychological distress, we used the Kessler-10 (K10) scale, consisting of 10 items indexing depressive but also anxiety and somatic symptoms, each item scored on a five-point scale (1=none, $2=\mathrm{a}$ little of the time, $3=$ some of the time, $4=$ most of the time, $5=$ all of the time). ${ }^{17}$ The internal reliability of items was 0.92 . A threshold of $\geq 30$ (the recommended international cut-off) was identified in a calibration study using a gold standard structured clinical interview in Timor-Leste. ${ }^{10} 16$

All measures were translated into Tetum, the most widely spoken language in Timor. Minor inconsistencies were addressed during piloting and the final versions were translated and back-translated using recommended international procedures.

\section{Field team}

The field team of 18 Timorese workers received a 2-week training followed by 2 months of experience field testing and piloting measures, supervised by the Australian team. Pairs of interviewers were required to achieve a $100 \%$ inter-rater reliability on the symptom measures prior to the study. Interviews were conducted in participants' homes and lasted an hour.

\section{STATISTICAL ANALYSIS}

Intraclass correlations for PTSS and psychological distress indicated negligible clustering $(<0.05)$ at the household level. We applied McNemar's test to assess for differences in PTSS and K10 prevalence between baseline and follow-up.

We tested two cross-sectional latent class analysis (LCA) models to examine for clustering of symptoms of PTSS and psychological distress at baseline and follow-up. We increased the number of classes serially, examining model fit indicators using the Bayesian Information Criterion (BIC), sample size-adjusted BIC (SS-BIC), and the Akaike's Information Criterion (AIC).$^{18} 19$ Lower values of these indicators suggest a better fit in comparing successive latent class models. In addition, we applied the Vuong-Lo-Mendell-Rubin (VLMR) and the LMR-adjusted likelihood ratio test which compare the fit of a latent class model of $n$ classes to one with $n+1$ classes. $^{20}$ In addition to these indicators, we judged the best fitting model based on the principles of parsimony and interpretability, the degree of class separation and the homogeneity of item conditional probabilities within classes.

We then tested an unconditional LTA model by examining measurement invariance of LTA parameters across time. The measurement component of the LTA identifies whether there are homogenous classes of individuals at each time point, whereas the structural (autoregressive) component examines for the transitioning of persons from one class to another over time. ${ }^{21} 22$

We used likelihood ratio tests to compare a model in which all parameter estimates (thresholds) were held equal within classes across time with one in which these thresholds were allowed to vary. ${ }^{21}$ To account for potential classification errors in the longitudinal LTA model, we used $\log$ ratios based on most likely class memberships obtained from each cross-sectional LCA. ${ }^{23}$

LTA analysis produced nine longitudinal classes; because of low representation in several longitudinal classes, ${ }^{24}$ we combined classes into rational groupings that were most relevant from a clinical and epidemiological perspective. In the final step, we applied multinomial logistic regression analysis using time 1 and time 2 covariates (age, sex, employment, TE exposure for both epochs of conflict, ongoing adversity and three indices of sense of injustice) to predict trajectories (the low-symptom trajectory acting as the reference group).

\section{RESULTS}

\section{Sociodemographic characteristics}

At baseline, 1271 of 1554 (81.5\%) adults completed interviews (non-response was due to refusal or relocation $(n=20)$; unavailability for interview $(n=10)$; and inability to make contact in spite of three visits to the dwelling $(\mathrm{n}=100))$. At follow-up, 1038 (549 women) participated, a retention rate of $84.5 \%$ (non-response at follow-up was due to relocation or refusal $(n=180)$ or incapacity of participant $(n=39))$. We excluded records with extensive missing data, resulting in a final cohort sample of 1022 persons (see online supplementary 1 ).

Table 1 reports the sociodemographic characteristics of the cohort sample. The majority lived in the rural area. The mean age increased from 33.9 years $(\mathrm{SD}=12.0)$ at baseline to 41.5 years $(\mathrm{SD}=13.5)$ at follow-up. Rates of marriage and education also increased at follow-up. There was a sevenfold increase in PTSS and a threefold 


\begin{tabular}{|c|c|c|c|c|}
\hline & $\begin{array}{l}2004 \\
(n=1022)\end{array}$ & $\begin{array}{l}\text { Per } \\
\text { cent }\end{array}$ & $\begin{array}{l}2010 \\
(n=1022)\end{array}$ & $\begin{array}{l}\text { Per } \\
\text { cent }\end{array}$ \\
\hline \multicolumn{5}{|l|}{ Sex } \\
\hline Female & 549 & 53.7 & 549 & 53.7 \\
\hline Male & 473 & 46.3 & 473 & 46.3 \\
\hline \multicolumn{5}{|l|}{ Location* } \\
\hline Rural & 595 & 59.3 & 600 & 58.7 \\
\hline Urban & 408 & 40.7 & 422 & 41.3 \\
\hline \multicolumn{5}{|l|}{ Age group (years) $†$} \\
\hline$<25$ & 255 & 25 & 42 & 4.1 \\
\hline 25-34 & 342 & 33.5 & 342 & 33.5 \\
\hline $35-54$ & 363 & 35.6 & 439 & 43 \\
\hline$\geq 55$ & 60 & 5.9 & 199 & 19.5 \\
\hline \multicolumn{5}{|l|}{ Marital status } \\
\hline Married & 732 & 71.6 & 801 & 78.4 \\
\hline Other & 290 & 28.4 & 221 & 21.6 \\
\hline \multicolumn{5}{|l|}{ Educational attainmentł } \\
\hline None or some & 580 & 57.3 & 499 & 48.8 \\
\hline Completed primary & 173 & 17.1 & 106 & 10.4 \\
\hline Completed secondary & 219 & 21.6 & 288 & 28.2 \\
\hline Completed tertiary & 41 & 4.1 & 129 & 12.6 \\
\hline \multicolumn{5}{|l|}{ Mental health outcomes } \\
\hline PTSD ( $\geq 2.2)$ & 23 & 2.3 & 171 & 16.7 \\
\hline $\begin{array}{l}\text { Severe psychological } \\
\text { distress }(\geq 30)\end{array}$ & 57 & 5.6 & 162 & 15.9 \\
\hline $\begin{array}{l}{ }^{*} \text { Nineteen missing in } 2004 . \\
\text { †Two missing in } 2004 \text {. } \\
\text { †Nine missing in } 2004 \text {. }\end{array}$ &  & & & \\
\hline
\end{tabular}

increase in severe psychological distress from baseline to follow-up. McNemar's test showed a statistical increase in the majority of symptoms of both measures $(p<0.001)$ over time, with the exception of nightmares $(p=0.855)$ and post-traumatic amnesia ( $\mathrm{p}=0.849$; table 2$)$.

\section{Cross-sectional LCA}

Table 3 indicates that a three-class model provided the best fit at baseline for combined PTSS and K10 symptoms as indicated by lower values of BIC, the SS-BIC and AIC compared with the two-class model. Although the VLMR and LMR indicated marginal improvement ( $p=0.46)$ over the two-class model, the three-class model had a higher classification accuracy (entropy 0.89 compared with 0.88$)$. An analogous three-class model was identified at follow-up, indicated by lower values of BIC, SS-BIC and AIC compared with the preceding model. Although the VLMR and LMR indicated statistical improvement for the addition of a fourth class, there was no increase in entropy over a three-class solution. In addition, two classes in the four-class model showed an identical structure, differing only in the magnitude of symptom conditional probabilities. We therefore adopted the more parsimonious and interpretable threeclass model at follow-up.
Figure 1 presents item probabilities for PTSS and severe psychological distress symptoms for the three-class LCA models at baseline (figure 1A) and follow-up (figure 1B), comprising a comorbid class, a psychological distress class and a low-symptom class.

The comorbid class at baseline (class 1, n=9, 0.9\%) was based on moderate-to-high probabilities $(>0.6)$ for PTSS and high probabilities for the majority of psychological distress symptoms. Class 2 at baseline showed low probabilities for PTSS and mid-range (0.2-0.5) probabilities for psychological distress. The majority of symptoms in the baseline low-symptom class (class 3, $n=735$, $72.2 \%)$ fell into the low-probability range $(>0.1)$.

At follow-up, the comorbid class (class 1, $\mathrm{n}=575$, $56.3 \%)$, was characterised by moderate probabilities (0.2-0.6) for symptoms of PTS and psychological distress. Symptoms of psychological distress in class 2 $(n=43,4.2 \%)$ had high probabilities, $(>0.6)$ whereas for PTSS, probabilities were comparatively low $(<0.1$; with the exception of behavioural avoidance, detachment and restricted affect, which fell into the low-to-moderate range $(0.2))$. The probabilities for most symptoms were low in the low-symptom class $(n=404,39.5 \%)$ with the exception of some items of psychological distress (fatigue, anxiety, restlessness, feeling everything is an effort, sadness) which fell into the low-to-moderate range $(0.2-0.3)$.

\section{Longitudinal LTA}

An unconditional longitudinal LTA comparing a restricted model (in which thresholds were held equal across the baseline and follow-up LCA models) with the unrestricted model (in which all parameter estimates were allowed to vary) indicated no significant difference in fit between the two models (log-likelihood difference $=1546, \mathrm{df}=308, \mathrm{p}=9.44$ ). Table 4 presents the unconditional transitional probabilities estimated for the three-class longitudinal LTA model.

Transitional probabilities can be interpreted as the probability of remaining in the same latent class (as indicated by diagonals in table 4) from baseline to follow-up, or the probability of transitioning from one latent class to another over time, represented by off-diagonal probabilities. Individuals assigned to the psychological distress and low-symptom classes at baseline recorded high-to-moderate probabilities of remaining in their respective classes at follow-up. In contrast, the comorbid class showed low-class stability, indicated by a low probability of remaining in that class over time. Off-diagonal probabilities indicated that individuals who transitioned from the comorbid class at baseline to a different class at follow-up had a moderate-to-high probability of transitioning into the low-symptom class, and a moderate probability of transitioning into the psychological distress class (table 4). Individuals who transitioned from the baseline psychological distress class showed a slightly higher probability of being assigned to the low-symptom class compared with the comorbid class at follow-up. 
Table 2 Prevalence of symptoms of post-traumatic stress disorder (PTSD) and severe psychological distress at time 1 (2004) and time 2 (2010-2011) among the Timorese cohort $(n=1022)$

\begin{tabular}{|c|c|c|c|c|c|c|}
\hline & & \multicolumn{2}{|c|}{ Time 1} & \multicolumn{2}{|c|}{ Time 2} & \multirow[b]{2}{*}{ p Value* } \\
\hline & & $\overline{\mathbf{N}}$ & Per cent & $\overline{\mathbf{N}}$ & Per cent & \\
\hline \multicolumn{7}{|c|}{ PTSD } \\
\hline 1 & Intrusive thoughts & 70 & 7 & 177 & 17 & $<0.0001$ \\
\hline 2 & Flashbacks & 32 & 3 & 70 & 7 & $<0.0001$ \\
\hline 3 & Nightmares & 63 & 6 & 65 & 6 & 0.855 \\
\hline 4 & Psychological/physiological reactions & 37 & 4 & 98 & 10 & $<0.001$ \\
\hline 5 & Cognitive avoidance & 49 & 5 & 79 & 8 & 0.008 \\
\hline 6 & Behavioural avoidance & 62 & 5 & 223 & 22 & $<0.0001$ \\
\hline 7 & Detachment & 83 & 6 & 147 & 14 & $<0.0001$ \\
\hline 8 & Restricted affect & 180 & 8 & 225 & 22 & 0.01 \\
\hline 9 & Anhedonia & 43 & 18 & 219 & 21 & $<0.0001$ \\
\hline 10 & Amnesia & 142 & 4 & 145 & 14 & 0.849 \\
\hline 11 & Foreshortened future & 32 & 14 & 79 & 8 & $<0.0001$ \\
\hline 12 & Startle response & 26 & 3 & 49 & 5 & 0.006 \\
\hline 13 & Concentration difficulties & 74 & 4 & 99 & 10 & 0.05 \\
\hline 14 & Insomnia & 69 & 7 & 130 & 13 & $<0.0001$ \\
\hline 15 & Feeling on guard & 23 & 8 & 65 & 6 & $<0.0001$ \\
\hline 16 & Anger outbursts & 22 & 2 & 69 & 7 & $<0.0001$ \\
\hline \multicolumn{7}{|c|}{ Severe psychological distress } \\
\hline 1 & Fatigue & 221 & 22 & 663 & 65 & $<0.0001$ \\
\hline 2 & Feeling anxious & 204 & 20 & 511 & 50 & $<0.0001$ \\
\hline 3 & Agitation & 103 & 10 & 264 & 26 & $<0.0001$ \\
\hline 4 & Hopelessness & 128 & 13 & 375 & 37 & $<0.0001$ \\
\hline 5 & Restlessness & 159 & 16 & 443 & 43 & $<0.0001$ \\
\hline 6 & Difficulties sitting still & 148 & 15 & 229 & 22 & $<0.0001$ \\
\hline 7 & Depressed & 146 & 14 & 283 & 28 & $<0.0001$ \\
\hline 8 & Feeling everything is an effort & 214 & 21 & 513 & 50 & $<0.0001$ \\
\hline 9 & Sadness & 149 & 15 & 403 & 39 & $<0.0001$ \\
\hline 10 & Worthlessness & 122 & 12 & 370 & 36 & $<0.0001$ \\
\hline
\end{tabular}

Those who transitioned from the baseline low-symptom class were more likely to be assigned to the psychological distress class compared with the comorbid class at follow-up.
Table 5 reports transitional latent class proportions based on the longitudinal LTA model. As expected, the largest number of persons $(\mathrm{n}=372,36.3 \%)$ in the comorbid class at follow-up comprised incident cases

Table 3 Goodness-of-fit statistics for cross-sectional latent class analysis of symptoms of PTSD and severe psychological distress at baseline and 6-year follow-up

\begin{tabular}{|c|c|c|c|c|c|c|c|c|c|c|}
\hline $\begin{array}{l}\text { Model } \\
\text { tested }\end{array}$ & FP & $\operatorname{LR} \chi^{2}$ & BIC & SSA-BIC & AIC & Entropy & VLMR & $\begin{array}{l}p \\
\text { Value }\end{array}$ & LMR & $\begin{array}{l}p \\
\text { Value }\end{array}$ \\
\hline \multicolumn{11}{|l|}{ Time 1} \\
\hline 1 Class & 26 & -7945.61 & 16007.39 & 15988.81 & 15943.22 & - & - & - & - & - \\
\hline 2 Class & 53 & -6694.81 & 13756.89 & 13588.56 & 13495.63 & 0.88 & -7945.61 & $<0.000$ & 2488.29 & $<0.000$ \\
\hline 3 Class & 80 & -6508.24 & 13570.85 & 13316.76 & 13176.49 & 0.89 & -6694.81 & 0.46 & 371.16 & 0.46 \\
\hline 4 Class & 107 & -6422.08 & 13585.61 & 13245.77 & 13058.15 & 0.86 & -6508.24 & 0.25 & 171.42 & 0.25 \\
\hline \multicolumn{11}{|c|}{ 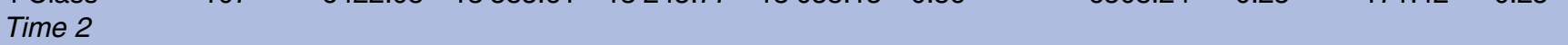 } \\
\hline 1 Class & 28 & -19911.67 & 40017.36 & 39928.43 & 39879.33 & - & - & - & - & - \\
\hline 2 Class & 53 & -10832.07 & 22031.40 & 21863.06 & 21770.13 & 0.87 & -12232.06 & $<0.000$ & 2786.17 & $<0.000$ \\
\hline 3 Class & 80 & -10324.41 & 21203.17 & 20949.08 & 20808.81 & 0.88 & -10832.07 & $<0.000$ & 1009.93 & $<0.000$ \\
\hline 4 Class & 107 & -10033.59 & 20808.64 & 20468.80 & 20281.18 & 0.88 & -10324.41 & $<0.000$ & 578.54 & $<0.000$ \\
\hline
\end{tabular}


Figure 1 Conditional symptom probabilities based on the three-class model for each time point. PTSD, post-traumatic stress disorder; T1, time 1; T2, time 2.
Latent classes of symptoms at $\mathrm{T} 1$

A

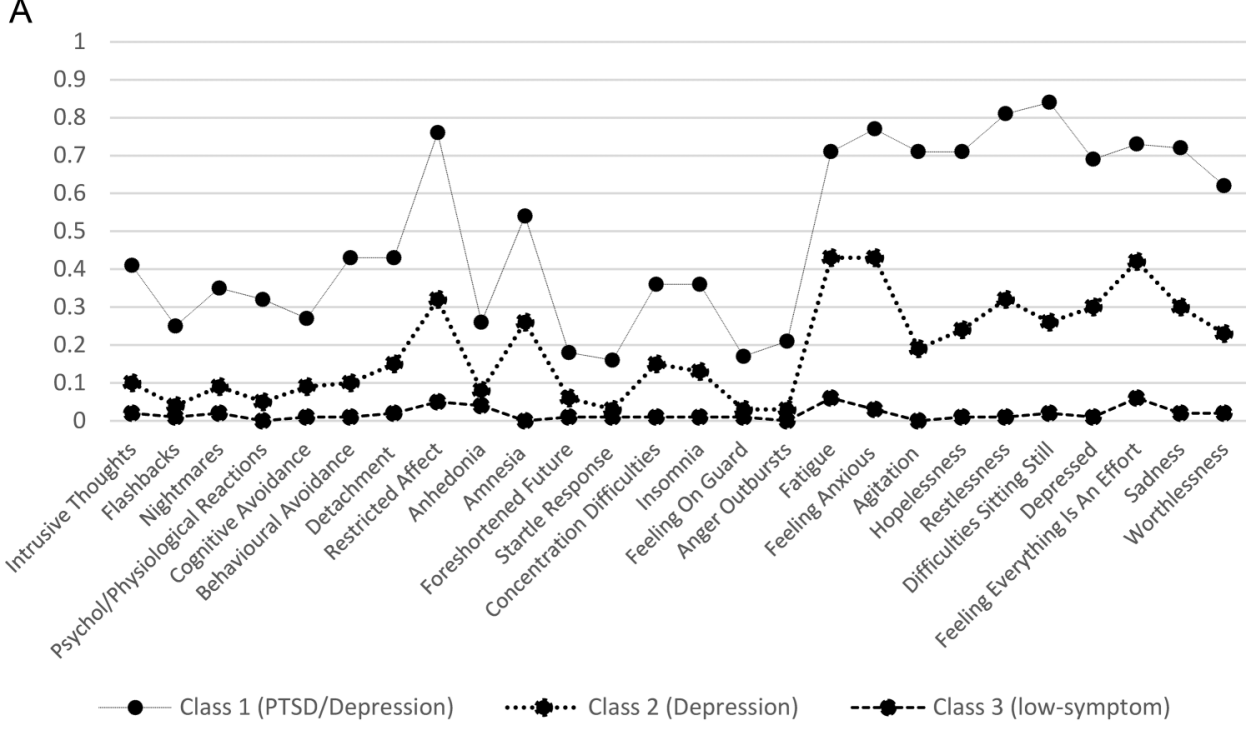

Latent classes of symptoms at T2

B

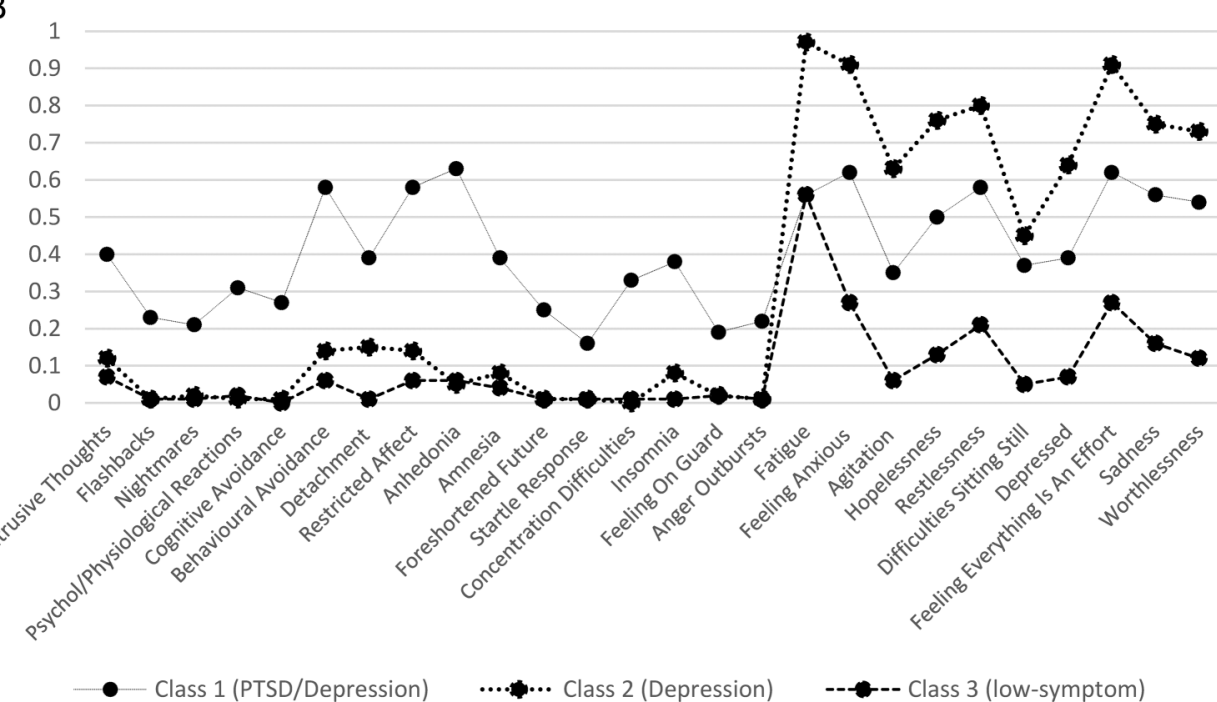

(ie, those who were in the low-symptom class at baseline).

\section{Predictors of longitudinal transitional class membership}

Given that several transitional classes included only a small portion of the sample $(<5 \%)$, we condensed these into clinically meaningful trajectories (see table 5 and figure 2 for derivation of the trajectories), comprising recovery $(n=213,20.8 \%$; defined by being in the comorbid or psychological distress class at baseline and in the low-symptom class at follow-up), a persisting trajectory $(\mathrm{n}=74,7.2 \%$; in one of the two morbid classes at baseline and at follow-up), an incident trajectory $(n=380,37.2 \%$; starting in the low-symptom class at baseline and transitioning into one of the two morbid classes at follow-up), and a low-symptom trajectory $(\mathrm{n}=355$, $34.7 \%$; in low-symptom class at both time points). The longitudinal transition patterns from baseline to follow-up are depicted in figure 2.
Table 6 shows that compared with the low-symptom trajectory, the recovery trajectory $(21 \%)$ was characterised by a greater sense of injustice for the period of independence. Persons in the persisting trajectory (comprising $7 \%$ of the sample) reported marginally higher unemployment at baseline, greater exposure to TEs for the two early periods of conflict (the Indonesian period and the humanitarian crisis leading to independence), ongoing poverty, family conflict and a sense of injustice for the period of independence (marginally significant) and contemporary times. Persons in the incident group $(37 \%)$ showed a trend for higher levels of unemployment at both time points, greater exposure to TEs for two periods, the humanitarian crisis extending into independence, and during the internal conflict, and higher levels of ongoing poverty and family conflict. In addition, they reported a sense of injustice for two periods, the Indonesian occupation and the period surrounding independence. 
Table 4 Transitional probabilities* based on the identified three-class longitudinal latent class model

\begin{tabular}{|c|c|c|c|}
\hline \multirow[b]{2}{*}{$\begin{array}{l}\text { Time } 1 \text { latent } \\
\text { status }\end{array}$} & \multicolumn{3}{|c|}{ Time 2 latent status } \\
\hline & Comorbid & $\begin{array}{l}\text { Severe } \\
\text { psychological } \\
\text { distress }\end{array}$ & $\begin{array}{l}\text { Low } \\
\text { symptom }\end{array}$ \\
\hline \multicolumn{4}{|c|}{ From time 1 to time 2} \\
\hline Comorbid & 0.156 & 0.269 & 0.575 \\
\hline $\begin{array}{l}\text { Severe } \\
\text { psychological } \\
\text { distress }\end{array}$ & 0.284 & 0.405 & 0.311 \\
\hline Low symptom & 0.353 & 0.428 & 0.219 \\
\hline \multicolumn{4}{|c|}{$\begin{array}{l}\text { *Diagonal transitional probabilities in bold, indicating the } \\
\text { probability of individuals at time } 1 \text { remaining in the same class at } \\
\text { time } 2 \text {. Off-diagonal probabilities indicate the probability of } \\
\text { transitioning from one latent class at time } 1 \text { to a different class at } \\
\text { time } 2 \text {. }\end{array}$} \\
\hline
\end{tabular}

\section{DISCUSSION}

Our analysis is the first to examine trajectories involving PTSS and general symptoms of distress following mass trauma in a low-income, postconflict society. Our findings suggest that the extent and timing of trauma exposure, the historical focus of a sense of injustice and conditions of ongoing adversity all contributed to shaping the trajectories of symptoms of PTS and severe psychological distress we identified among Timorese over a 6-year follow-up period.

There were similarities between our findings and the trajectories observed among survivors of natural disasters and accidents in high-income countries, ${ }^{6} 7$ in that we identified both a low-symptom (the majority) and a persisting symptom trajectory. Given the conflict-affected nature of the sample, our study was able to focus specifically on the historical factors associated with poor symptom outcomes at follow-up. Those with persisting symptoms reported increased exposure to trauma during the earlier periods of conflict, whereas new-onset cases were unique in reporting greater trauma exposure during the recent period of internal conflict. The one epoch in common was the humanitarian crisis of 1999 which had pervasive effects in exposing the population to trauma. Both groups reported ongoing adversities related to poverty and family conflict. The persisting and new-onset groups had in common a sense of injustice surrounding national independence; in addition, the former group reported a sense of injustice for contemporary times whereas the latter for the Indonesian period. The considerable percentage $(21 \%)$ who showed recovery over time were characterised primarily by the absence of risk factors, the only exception being sense of injustice related to the period surrounding independence.

The unique aspects of the persisting symptom group are important to note. That group was the only subpopulation reporting high exposure to traumas during the period of the Indonesian occupation when the most extreme forms of trauma (torture, disappearances, atrocities and the like) occurred in the context of a state of prolonged and systematic persecution. ${ }^{25}$ The pattern observed is consistent with cross-sectional data from other countries experiencing extensive persecution, for example, Cambodia, which has shown that traumas experienced in these settings can have long-term effects on the mental health of the population. ${ }^{26}$ The persisting group also was unique in reporting a sense of injustice related to contemporary times. It is well known that many veterans of the armed resistance struggle in Timor-Leste have continued to hold grievances against the postindependence authorities for not recognising (either symbolically or materially) the sacrifices militants made during the conflict, particularly given that the stigma and discrimination that their families experienced at the time have contributed to ongoing disadvantages in the postindependence period. ${ }^{25}$

Debate continues regarding the factors that contribute to the late-onset PTSS trajectory identified in longitudinal studies in high-income countries, ${ }^{27} 28$ specifically whether they represent a population already sensitised to trauma who are genuinely 'delayed' in symptom onset or reflect a new-onset group responding mainly to

\begin{tabular}{|c|c|c|c|}
\hline LTA class & Time 1 & Time 2 & $N(n=1022)$ \\
\hline 1 & Class 1 (psychological distress) & Class 3 (low symptom) & 213 \\
\hline 2 & Class 1 (psychological distress) & Class 1 (psychological distress) & 43 \\
\hline 3 & Class 1 (psychological distress) & Class 2 (comorbid) & 22 \\
\hline 4 & Class 2 (comorbid) & Class 3 (low symptom) & 0 \\
\hline 5 & Class 2 (comorbid) & Class 1 (psychological distress) & 0 \\
\hline 6 & Class 2 (comorbid) & Class 2 (comorbid) & 9 \\
\hline 7 & Class 3 (low symptom) & Class 3 (low symptom) & 355 \\
\hline 8 & Class 3 (low symptom) & Class 1 (psychological distress) & 0 \\
\hline 9 & Class 3 (low symptom) & Class 2 (comorbid) & 380 \\
\hline
\end{tabular}


Figure 2 Longitudinal transitional patterns from time 1 to time 2 and derivation of four core symptom trajectories $(n=1022)$.

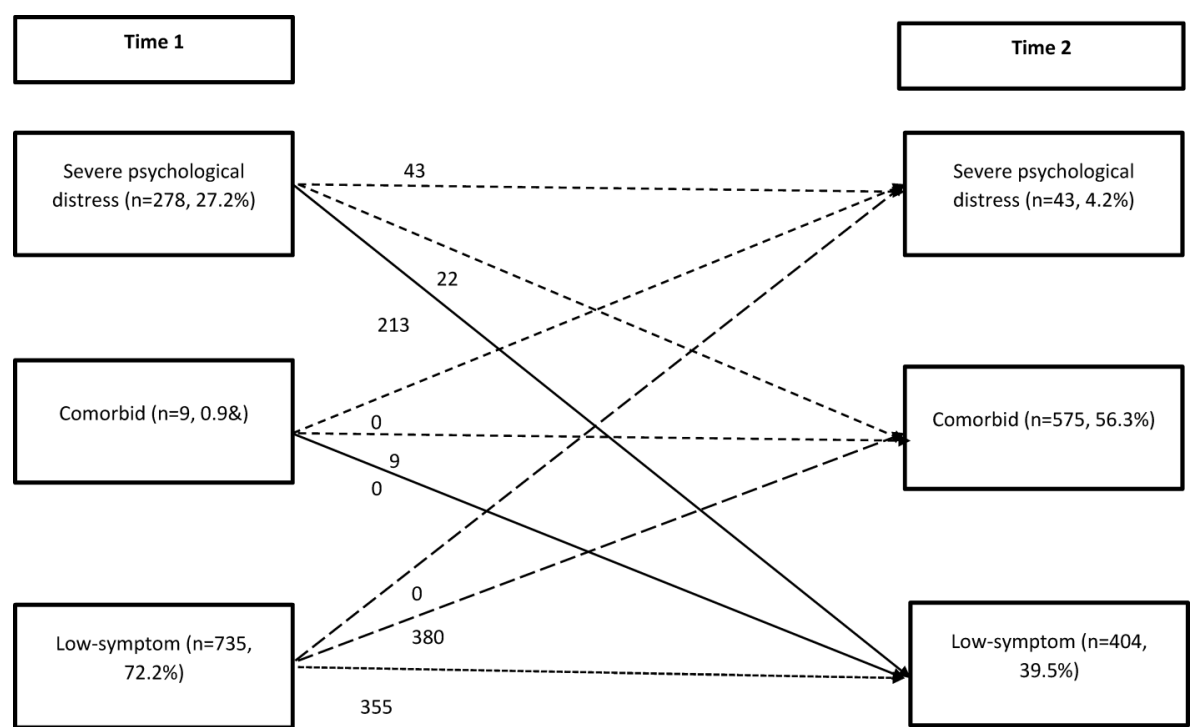

Recovery trajectory $\rightarrow$ Persisting trajectory.$->$ Incident trajectory.$--->$ low symptom trajectory ...... $>$ recurrent trauma during the follow-up period. ${ }^{27}$ Our findings indicated that in the Timor-Leste context, the new-onset group was characterised both by prior sensitisation to trauma and a proximate trigger, that is, exposure to trauma during the period of internal conflict (2006-2007) which occurred in the interregnum between baseline and follow-up. The internal conflict of 2006-2007 involved factions within the country who were disaffected politically and economically. During this period, attempts were made to assassinate both the president and prime minister of the country. ${ }^{8}$ It seems likely, therefore, that those with persisting grievances arising from the earlier periods of conflict were more likely to be drawn into the internecine violence that broke out in 2006-2007, placing them at increased risk of further exposure to trauma and hence onset of PTSS and severe psychological distress in the aftermath (as detected at follow-up). The differential patterns of

Table 6 Multinomial logistic regression examining predictors of composite trajectories derived from combining longitudinal latent classes $(n=1022)$

\begin{tabular}{|c|c|c|c|}
\hline \multirow[b]{2}{*}{ Predictors } & \multicolumn{3}{|l|}{ OR $(95 \% \mathrm{Cl})$} \\
\hline & Recovery ( $n=213,20.8 \%)$ & $\begin{array}{l}\text { Persisting morbidity } \\
(\mathrm{n}=74,7.2 \%)\end{array}$ & $\begin{array}{l}\text { Incident (new onset) } \\
(\mathrm{n}=380,37.2 \%)\end{array}$ \\
\hline \multicolumn{4}{|c|}{ Compared with low-symptom trajectory $(n=355,34.7 \%)$} \\
\hline Sex (male) & $0.77(0.42$ to 1.40$)$ & $1.11(0.77$ to 1.59$)$ & $0.85(0.58$ to 1.25$)$ \\
\hline Time 1 age & $1.01(0.96$ to 1.05$)$ & 0.99 (0.96 to 1.02$)$ & 0.99 (0.96 to 1.01$)$ \\
\hline Time 2 age & $0.99(0.94$ to 1.04$)$ & 0.99 (0.97 to 1.02$)$ & 1.01 (0.99 to 1.04$)$ \\
\hline Time 1 unemployment & $0.71(0.37$ to 1.36$)$ & $1.30(0.84$ to 2.01$)$ & $1.28(0.81$ to 2.03$)$ \\
\hline Time 2 unemployment & $1.37(0.74$ to 2.54$)$ & $1.12(0.77$ to 1.62$)$ & $1.32(0.89$ to 1.95$)$ \\
\hline \multicolumn{4}{|c|}{ Conflict-related TEs† spanning three historical epochs } \\
\hline Indonesian occupation & $1.04(0.77$ to 1.41$)$ & $1.21^{\star \star}(1.04$ to 1.42$)$ & $1.02(0.85$ to 1.24$)$ \\
\hline Humanitarian crisis through to independence & $1.00(0.82$ to 1.23$)$ & $1.37^{\star \star}(1.33$ to 1.54$)$ & $1.15^{\star *}(1.01$ to 1.30$)$ \\
\hline Internal conflict & $1.00(0.82$ to 1.23$)$ & $1.06(0.95$ to 1.19$)$ & $1.19^{\star *}(1.07$ to 1.33$)$ \\
\hline \multicolumn{4}{|l|}{ Ongoing adversities } \\
\hline Poverty & $0.96(0.88$ to 1.04$)$ & $1.10^{* *}(1.04$ to 1.15$)$ & $1.16^{\star \star}(1.10$ to 1.23$)$ \\
\hline Family conflict & $0.82(0.41$ to 1.65$)$ & $1.63^{\star *}(1.19$ to 2.24$)$ & $1.93^{\star *}(1.41$ to 2.63$)$ \\
\hline Communal conflict & $0.84(0.46$ to 1.51$)$ & $0.94(0.71$ to 1.25$)$ & 1.04 (0.78 to 1.39$)$ \\
\hline \multicolumn{4}{|l|}{ Sense of injustice } \\
\hline Indonesian occupation & $1.76(0.95$ to 3.26$)$ & $1.09(0.77$ to 1.55$)$ & $1.51^{*}(1.04$ to 2.20$)$ \\
\hline Independence & $3.52^{\star \star}(1.92$ to 6.44$)$ & $1.42(0.97$ to 2.08$)$ & $1.67^{*}(1.12$ to 2.49$)$ \\
\hline Contemporary times & $1.40(0.79$ to 2.48$)$ & $1.62^{* \star}(1.14$ to 2.29$)$ & 1.31 (0.90 to 1.89$)$ \\
\hline
\end{tabular}

${ }^{* *} p<0.01,{ }^{*} p<0.05$.

†Traumatic events (TEs; applied as count variables) for the Indonesian occupation were assessed at baseline and the remaining epochs at follow-up. Ongoing adversities were assessed at follow-up. The three historical periods of injustice were recorded at time 2. 
covariates that emerged therefore add to the contextual validity and historical specificity of our findings, demonstrating the complex interaction between the extent and timing of exposure to conflict-related TEs, the historical focus of a sense of injustice, and ongoing adversity in shaping the longitudinal course of symptom trajectories over the 6-year period.

It is now well recognised that countries emerging from prolonged periods of conflict are at substantial risk of recurrent episodes of internal violence in the early aftermath. ${ }^{29}$ From a policy perspective, therefore, our findings reinforce the importance of establishing durable conditions of peace in the aftermath of prolonged conflict, a principle underscored by the large contribution the internal conflict made to the symptom trajectory of the incident group, the subpopulation that accounted substantially for the manifold increase in PTSS and severe psychological distress symptoms identified at follow-up. Furthermore, ensuring that economic recovery advances the lives of all citizens is vital not only to overcoming poverty but to improving mental health outcomes and overcoming past grievances, particularly among the subpopulation actively involved in the earlier conflict. Equally, strategies to reduce family conflict, which in its extreme form may manifest in intimate partner violence, a problem common to Timor and many postconflict countries, is a vital element in promoting mental health.

Finally, addressing a persisting sense of injustice is an important focus for social policy. Although a truth and reconciliation commission was implemented in Timor-Leste soon after independence, there is evidence that many survivors of human rights abuses remained aggrieved at the end of the process, in part because the major perpetrators of atrocities and political murders evaded prosecution by fleeing to Indonesia. ${ }^{30}$ An additional source of the sense of injustice relates to the lack of redress concerning the extensive losses, material and personal, experienced by the Timorese. Postindependence, the political leaders of the country have tended to encourage reconciliation with Indonesia (an important consideration given the size and influence of this neighbouring country) with less of an emphasis on acknowledging and addressing past atrocities. Our findings underscore, however, the importance of addressing the sense of injustice in postconflict communities given the potential for such persisting feelings to contribute to further communal violence (a pattern suggested by the new-onset group), in turn increasing the prevalence of PTSS and related symptoms.

Nevertheless, it also is important to acknowledge that survivors can exhibit a pattern of resiliency in spite of exposure to injustices. Studies have found that community and family support in particular can promote resiliency among survivors in spite of their legitimate sense of injustice arising from exposure to past human rights violations. ${ }^{31-34}$ We note that our community-derived index of injustice was based on an in-depth inquiry into specific and direct experiences of participants in each of three successive historical epochs. It seems likely, however, that the sense of injustice recorded by participants was influenced by a wider range of political, social, cultural and ecological factors, their individual reports representing a distillation of grievances that had accumulated over time. Further studies are needed to elucidate the specific factors that contribute to a sense of injustice and the processes by which survivors cope with these feelings, including the possible protective cultural, social and family influences that may play a role in shaping resilience both at the individual and collective levels.

Although it is unlikely that any single policy or strategy is capable of addressing fully the grievances arising from past conflict and persecution, a range of initiatives pursued over time may assist in ameliorating feelings of injustice, including assertive efforts to bring perpetrators to account, the holding of events to register public recognition of the sacrifices made by survivors, promotion of culturally appropriate memorial ceremonies and/or religious rituals for those who were lost during the period of persecution, and the provision of adequate compensation for survivors and their families.

We note the key limitations of the study. Recruitment was restricted to two localities and the sample cannot be regarded as representative of the broader population of Timor-Leste. Replication of our findings in other areas of Timor-Leste and in postconflict countries worldwide is necessary to test the generalisability of these findings. We achieved a high response and retention rate, an outcome which is likely to reflect the team's sustained efforts in building a long-term partnership with Timorese agencies and the community, reflected, for example, in our active role in developing the national mental health service in the country. ${ }^{35}$

While the mental health measures used were systematically adapted to the culture and language of the country and validated against a structured clinical interview, they are not designed to capture culture-specific idioms of distress. Focusing on symptoms of PTS and severe psychological distress over the past 4 weeks is likely to have improved accuracy of recall but also prevented us from determining the longer term course of symptoms: in particular, whether the so-named persisting group experienced chronic, fluctuating or a recurrence of symptoms from baseline to follow-up. Reports of trauma may be subject both to anamnestic bias and distortions arising from the suppression of traumatic memories in order to prevent triggering distress; nevertheless, we note that the pattern of TEs documented across the sample as a whole is consistent with the known history of conflict in Timor-Leste.

\section{CONCLUSIONS}

Our findings identified four composite trajectories of mental health symptoms in the aftermath of mass 
conflict in Timor-Leste, comprising a recovery trajectory, a persistent trajectory, an incident trajectory and a low-symptom trajectory. Both the persistent and incident trajectories were associated with stress arising from conditions of adversity and family conflict. The persistent trajectory was unique in being associated with greater exposure to TEs during the Indonesian occupation, whereas those in the incident trajectory reported greater TE exposure during the period of internal conflict that occurred between baseline and follow-up. The recovery trajectory was characterised primarily by the absence of these risk factors. The persistent trajectory experienced a sense of injustice for recent, times whereas the incident group's focus was on earlier periods of conflict. Our findings therefore underscore the importance of a combination of factors, including the timing and extent of trauma, the historical focus of participants' sense of injustice, and ongoing adversity, in influencing the longitudinal trajectories of common mental health symptoms among populations exposed to mass conflict and persecution.

\section{Author affiliations}

${ }^{1}$ Psychiatry Research and Teaching Unit, University of New South Wales, Sydney, New South Wales, Australia

${ }^{2}$ Academic Mental Health Unit, Mental Health Centre, Liverpool Hospital, Sydney, New South Wales, Australia

${ }^{3}$ St John of God Richmond Hospital, School of Psychiatry, University of New South Wales

${ }^{4}$ Alola Foundation, Dili, Timor-Leste

Twitter Follow Alvin Kuowei Tay at @tayku943

Acknowledgements The authors thank the following members of our team for their contributions to this work: Lazaro Lelan Sila, Titolivio Candido Simoes, Emanuel bas Fernandes Lelan, Plasido do Carmo Viera, Maria Ribeiro Seixas and Dr Belinda Liddell.

Contributors AKT conceptualised, analysed, interpreted and drafted the manuscript. DMS interpreted the data, drafted and revised the manuscript. SR and ZS revised and approved the manuscript. NT, ZS and CS performed the survey.

Funding This work was supported by National Medical and Health Research Council Australia grant number (RM08333).

Competing interests None declared.

Patient consent Obtained.

Ethics approval The study was approved by the Human Research Ethics Committee of the University of New South Wales, the Ministry of Health of Timor-Leste, and the chiefs of each village.

Provenance and peer review Not commissioned; externally peer reviewed.

Data sharing statement No additional data are available.

Open Access This is an Open Access article distributed in accordance with the Creative Commons Attribution Non Commercial (CC BY-NC 4.0) license, which permits others to distribute, remix, adapt, build upon this work noncommercially, and license their derivative works on different terms, provided the original work is properly cited and the use is non-commercial. See: http:// creativecommons.org/licenses/by-nc/4.0/

\section{REFERENCES}

1. Kohrt BA, Hruschka DJ, Worthman CM, et al. Political violence and mental health in Nepal: prospective study. Br J Psychiatry 2012;201:268-75.
2. Westermeyer J, Neider J, Callies A. Psychosocial adjustment of Hmong refugees during their first decade in the United States. A longitudinal study. J Nerv Ment Dis 1989;177:132-9.

3. Mollica RF, Caridad KR, Massagli MP. Longitudinal study of posttraumatic stress disorder, depression, and changes in traumatic memories over time in Bosnian refugees. J Nerv Ment Dis 2007;195:572-9.

4. Mollica RF, Sarajlic N, Chernoff M, et al. Longitudinal study of psychiatric symptoms, disability, mortality, and emigration among Bosnian refugees. JAMA 2001;286:546-54.

5. Neria Y, Olfson M, Gameroff MJ, et al. Long-term course of probable PTSD after the 9/11 attacks: a study in urban primary care. J Trauma Stress 2010;23:474-82.

6. Bryant RA, O'Donnell ML, Creamer M, et al. A multisite analysis of the fluctuating course of posttraumatic stress disorder. JAMA Psychiatry 2013;70:839-46.

7. Forbes D, Nickerson A, Alkemade N, et al. Longitudinal analysis of latent classes of psychopathology and patterns of class migration in survivors of severe injury. J Clin Psychiatry 2015;76:1193-9.

8. Kiernan B. The demography of genocide in Southeast Asia: the deaths tools in Cambodia, 1975-79, and East Timor, 1975-80. Crit Asian Stud 2003;35:585-97.

9. Silove D. Health and human rights of the East Timorese. Lancet 1999;353:2067.

10. Silove D, Liddell B, Rees S, et al. Effects of recurrent violence on post-traumatic stress disorder and severe distress in conflict-affected Timor-Leste: a 6-year longitudinal study. Lancet Glob Health 2014;2: e293-300.

11. Kessler RC, Rose S, Koenen KC, et al. How well can post-traumatic stress disorder be predicted from pre-trauma risk factors? An exploratory study in the WHO World Mental Health Surveys. World Psychiatry 2014;13:265-74.

12. Brooks R, Silove D, Steel Z, et al. Explosive anger in postconflict Timor Leste: Interaction of socio-economic disadvantage and past human rights-related trauma. J Affect Disord 2011;131:268-76.

13. Silove D, Brooks R, Bateman Steel CR, et al. Explosive anger as a response to human rights violations in post-conflict Timor-Leste. Soc Sci Med 2009;69:670-7.

14. Rees S, Silove D, Verdial T, et al. Intermittent explosive disorder amongst women in conflict affected Timor-Leste: associations with human rights trauma, ongoing violence, poverty, and injustice. PLoS ONE 2013;8:e69207.

15. Mollica RF, Caspi-Yavin Y, Bollini $P$, et al. The Harvard Trauma Questionnaire: validating a cross-cultural instrument for measuring torture, trauma, and posttraumatic stress disorder in Indochinese refugees. J Nerv Ment Dis 1992;180:111-16.

16. Liddell BJ, Silove D, Tay K, et al. Achieving convergence between a community-based measure of explosive anger and a clinical interview for intermittent explosive disorder in Timor-Leste. J Affect Disord 2013;150:1242-6.

17. Furukawa TA, Kessler RC, Slade T, et al. The performance of the $\mathrm{K} 6$ and K10 screening scales for psychological distress in The Australian National Survey of Mental Health and Well-Being. Psychol Med 2003;33:357-62.

18. McGCutcheon AC. Latent class analysis. Beverly Hills: CA: Sage, 1987.

19. Nylund KL, Asparouhov T, Muthen B. Deciding on the number of classes in latent class analysis and growth mixture modeling: a Monte Carlo simulation study. Struct Equation Model 2007; 14:535-69.

20. Collins LM, Fidler PL, Wugalter SE, et al. Goodness-of-fit testing for latent class models. Multivariate Behav Res 1993;28:375-89.

21. Collins LM, Lanza ST. Latent class and latent transition analysis: with applications in the social, behavioral, and health sciences. Wiley, 2009.

22. Nylund KL. Latent transition analysis: modeling extensions an application to peer victimization. UCLA, 2007.

23. Muthen B. Three-step latent transition analysis. Modern Modeling Methods Conference; University of Conneticut Mplus, 2013:1-15.

24. Muthen B, Asparouhov T. LTA in Mplus: Transition Probabilities Influenced by Covariates. Mplus Web Notes: No.13. 2011.

25. Modvig J, Pagaduan-Lopez J, Rodenburg J, et al. Torture and trauma in post-conflict East Timor. Lancet 2000;356:1763.

26. Mollica RF, Brooks R, Tor S, et al. The enduring mental health impact of mass violence: a community comparison study of Cambodian civilians living in Cambodia and Thailand. Int J Soc Psychiatry 2014;60:6-20.

27. Andrews B, Brewin CR, Philpott R, et al. Delayed-onset posttraumatic stress disorder: a systematic review of the evidence. Am J Psychiatry 2007;164:1319-26. 
28. Frueh BC, Grubaugh AL, Yeager DE, et al. Delayed-onset post-traumatic stress disorder among war veterans in primary care clinics. Br J Psychiatry 2009;194:515-20.

29. Panter-Brick C. Conflict, violence, and health: setting a new interdisciplinary agenda. Soc Sci Med 2010;70:1-6.

30. Silove D, Zwi AB, le Touze D. Do truth commissions heal? The East Timor experience. Lancet 2006;367:1222-4.

31. Thomas FC, Roberts B, Luitel NP, et al. Resilience of refugees displaced in the developing world: a qualitative analysis of strengths and struggles of urban refugees in Nepal. Confl Health 2011;5:20.

32. Zraly M, Nyirazinyoye L. Don't let the suffering make you fade away: an ethnographic study of resilience among survivors of genocide-rape in southern Rwanda. Soc Sci Med 2010;70: 1656-64.

33. Nguyen-Gillham V, Giacaman R, Naser G, et al. Normalising the abnormal: Palestinian youth and the contradictions of resilience in protracted conflict. Health Soc Care Community 2008;16:291-8.

34. Suarez EB. The association between post-traumatic stress-related symptoms, resilience, current stress and past exposure to violence: a cross sectional study of the survival of Quechua women in the aftermath of the Peruvian armed conflict. Confl Health 2013;7:21.

35. Silove D, Rees S, Tam N, et al. Staff management and capacity building under conditions of insecurity: lessons from developing mental health service and research programs in post-conflict Timor-Leste. Australas Psychiatry 2011;19(Suppl 1):S90-4. 